\title{
Atrial fibrillation and heart failure in seven nursing homes
}

\author{
Kjell Krüger ${ }^{1}$, Marie Sandli' ${ }^{2}$, Jonn-Terje Geitung ${ }^{3}$, Geir Egil Eide ${ }^{4,5}$, Anders Grimsmo ${ }^{6}$ \\ 1.Loevaasen Teaching Nursing Home, Municipality of Bergen, Norway. 2. Haukeland University Hospital, Bergen, Norway. \\ 3. Haraldsplass Hospital, Bergen, Norway. 4. Centre for Clinical Research, Haukeland University Hospital, Bergen, Norway. \\ 5. Research Group on Lifestyle Epidemiology, Department of Public Health and Primary Health Care, University of Bergen, \\ Norway. 6. Department of Public Health and General Practice, Norwegian University of Science and Technology, \\ Trondheim, Norway.
}

Correspondence: Kjell Krüger. Address: Loevaasen Teaching Nursing Home, Municipality of Bergen, Loevaasveien 26, NO-5145 Fyllingsdalen, Norway. Telephone: 479-085-5632. E-mail: kjell.kruger@gmail.com

Received: January 5, 2012 Accepted: February 21, 2012 Published: November 1, 2012

DOI : 10.5430/jnep.v2n4p22 URL: http://dx.doi.org/10.5430/jnep.v2n4p22

\section{Abstract}

Objectives: Previous research suggests that blood-thinning treatment for patients with atrial fibrillation as well as treatment for patients with heart failure is not adequate among the elderly. We tested this among long-term patients in nursing homes.

Methods: Information about the patients $(\mathrm{n}=513)$ was collected during the period March-April 2008. Data collection consisted of electrocardiography, particulars of any stroke suffered and copying medication records. A standardized set of blood samples was analyzed.

Results: Of the 91 atrial fibrillation patients, $14.3 \%$ were anticoagulated with warfarin. $42.0 \%$ of the patients with atrial fibrillation had no form of antithrombotic treatment. Prevalence of atrial fibrillation was $18.8 \%$ and high B-type natriuretic peptide (ProBNP $>225 \mathrm{pmol} / \mathrm{L}$ ) $13.2 \%$. Of the patients with both stroke and atrial fibrillation, $24.3 \%$ were given warfarin. Of the 59 patients with ProBNP $>225 \mathrm{pmol} / \mathrm{L}$ and adequate renal function (eGFR $>50 \mathrm{ml} / \mathrm{min}$ ), $22.0 \%$ were given $\mathrm{ACE} / \mathrm{A} 2 \mathrm{~B}$.

Conclusions: The warfarin treatment rate was lower than recommended for patients with atrial fibrillation in nursing homes, as was probably the use of ACE-inhibitors to heart -failure patients. We found significant differences between the nursing homes with regard to treatment rate. Atrial fibrillation and heart failure case finding and monitoring in nursing homes needs to be improved and simple tools like recording and reporting irregular pulse by doctors and nurses and measure ProBNP on a regular basis may improve this.

\section{Key words}

Nursing home, Atrial fibrillation, Heart failure, Drugs, Long-term care, Chronic disease

\section{I ntroduction}

Norway has 4.6 million inhabitants, 55 public hospitals, 41,052 nursing home beds and 1,796 beds in old people's homes; $96.8 \%$ of nursing home beds are in single rooms and $43.3 \%$ of all deaths (total 41,342) are in nursing institutions ${ }^{[1]}$. The 
healthcare system is split into first and second line services. First line services are administered and financed by the municipalities $(\mathrm{N}=431)$. First line covers general practice (GP) services, mother and child care, home-care and nursing homes $(\mathrm{N}=900)$. The second line contains the 55 hospitals and specialist services (including private specialists). Second line is administered and financed directly by the state.

It is expected that nursing homes will play an important role in healthcare delivery in the years ahead. The population is growing older and patients admitted to hospitals are being discharged earlier. A Norwegian white paper states that a reform is needed to ensure collaboration between primary care and hospitals. After US, Norway (2009) spends the most money per capita on health in the world (www.oecd.org), but does not get the most in return for the investments. Poor cooperation between first- and second line services is regarded as the main obstacle to improvements ${ }^{[2]}$. Among several proposals, the white paper points to accomplishments involving early discharges from hospitals to nursing homes which offer more advanced medical care and structured rehabilitation programs than previously. Quality in the nursing homes will thus be under pressure, expectations of services will rise and clinical complexity will grow. New strategies and more knowledge about the nursing home population are needed to meet this situation.

Two of the most frequent diagnoses among the elderly (>75) are atrial fibrillation (AF) and congestive heart failure. The prevalence of AF has not been studied in Norwegian nursing homes, nor has the way AF is treated. The question of under-treatment of heart failure in nursing homes has been raised earlier ${ }^{[3]}$.

$\mathrm{AF}$ is an independent risk factor for developing a stroke ${ }^{[4]}$, and in the elderly it is one of the most important causes of stroke ${ }^{[5]}$. The current guidelines state that most patients over the age of 75 with atrial fibrillation should be anticoagulated with warfarin. However, increasing age often leads to lower treatment rate than among younger patients ${ }^{[6,7]}$. Stroke risk in AF patients can be estimated using the CHADS2 score, which is a clinical prediction rule for estimating the risk of stroke in patients with non-rheumatic atrial fibrillation ${ }^{[8]}$. "Patients are given points on the basis of clinical variables - heart failure: 1 point, hypertension: 1 point, over 75 years of age: 1 point, diabetes: 1 point, previous stroke or transient ischaemic attack (TIA): 2 points. The annual risk of stroke is: CHADS2 score $0: 1.9 \%, 1: 2.8 \%, 2: 4.0 \%, 3: 5.9 \%, 4: 8.5 \%$, 5: $12.5 \%, 6: 18.2 \%$ ". By one (1) point warfarin or aspirin is recommended, by $\geqslant 2$ points warfarin treatment is recommended.

To estimate the risk of bleeding for AF patients on warfarin treatment, bleeding risk scores can be used ${ }^{[9]}$ : "Bleeding risk score $=0.49 \cdot \mathrm{X}($ Age $>70)+0.32 \cdot \mathrm{X}($ Female $)+0.58 \cdot \mathrm{X}($ Remote bleed $)+0.62 \cdot \mathrm{X}($ Recent bleed $)+0.71 \cdot \mathrm{X}($ Alcohol/Drug Abuse $)+0.27 \cdot \mathrm{X}$ (Diabetes) $+0.86 \cdot \mathrm{X}$ (Anaemia) $+0.32 \cdot \mathrm{X}$ (Antiplatelet), where $\mathrm{X}$ equals 1 when the specific characteristic is present and 0 otherwise. Bleeding risk scores of $>1.07,>1.07$ but $<2.19$, and $>2.19$, respectively, are classified as low, moderate and high risk. Low-risk individuals have $0.9 \%$ bleeding risk, moderate-risk $2.0 \%$ and high-risk individuals 5.4\%". In the study cited the high-risk bleeding individuals (5.6\% bleeding risk) had a 7\% stroke risk.

Simple diagnostic tests are needed in nursing homes to diagnose the most frequent conditions. Transports to hospitals may be exhausting for frail and old nursing home patients. Research shows that ProBNP, which is an amino acid secreted by the ventricles of the heart in response to excessive stretching of heart muscle cells (cardiomyocytes), provides useful diagnostic information supplementary to clinical examination in order to diagnose untreated heart failure in the elderly ${ }^{[10]}$. This refers both to left ventricular function ${ }^{[11]}$ and diastolic dysfunction ${ }^{[12]}$. To monitor heart failure treatment using repeated measurements of ProBNP in blood is probably better than traditional methods like clinical examination and echocardiography ${ }^{[13]}$.

We wanted to investigate to what degree long-term nursing home residents with $\mathrm{AF}$ received antithrombotic treatment and to what extent patients with NT-proBNP above $225 \mathrm{pmol} / \mathrm{L}$ were treated with angiotensin-converting enzyme (ACE) inhibitors/A2 blockers, beta-blockers, statins and diuretics, and to shed light on the biasing effect of renal failure, weight and age on ProBNP. We also wanted to study whether there were differences in treatment between the nursing homes. 
The study was approved by the Regional Ethics Committee of Western Norway.

\section{Materials and methods}

Bergen has 250,000 inhabitants and 37 nursing homes (2,300 beds). The number of beds ranges from 20 to 189. Seven nursing homes in Bergen participated in this study. Only long-term patients $(n=513)$ were included. The nursing homes were comparable in terms of nursing staff, financing and gender distribution.

Information about the patients was gathered during the period March-April 2008. 24 medical students conducted the data collection, which consisted of weight, details of any stroke suffered and copying of drug charts. Electrocardiography was conducted to diagnose AF and a standardized set of blood samples were analyzed at the laboratory at the Bethany Hospital (haemoglobin, B-type natriuretic peptide (ProBNP), sodium, potassium, calcium, albumin, creatinine, blood urea nitrogen, urate, estimated glomerular filtration rate (eGFR)). 447 of the patients were blood-tested and 484 ECG'ed. 488 of the patients were weighed. It was possible to conclude if the patient had undergone a stroke in 462 of the patients. Complete medication records existed for all patients.

We used ProBNP $>225 \mathrm{pmol} / \mathrm{L}$ to define patients with heart failure. To understand the degree of the biasing effects of age, weight and renal function on ProBNP-levels in this population, we performed bivariate analyses of the factors mentioned and quantified explained variation by the determination coefficient $\left(\mathrm{R}^{2}\right)$. We also estimated non-parametric correlation (Spearman's) between ProBNP and eGFR, as renal function is considered the most important biasing factor for ProBNP. To try to find a predictive equation taking all biasing factors into consideration, a multiple linear regression analysis of the square root of proBNP on age, weight and the square root of eGFR was performed.

The recorded data were keyed into an Excel worksheet and the drugs coded according to the Anatomical Therapeutic Chemical Drug Register (ATC). Frequency counts were performed in Excel, but the statistical analysis software JMP version 8 (from SAS), was used for general statistical analysis. To analyze differences in average of continuous data (e.g. ProBNP) the Tukey-Kramer (Honestly Significant Difference) multiple-comparison method was used as a parametric method (- assumes that the data has come from a type of probability distribution and makes inferences about the parameters of the distribution) and the Wilcoxon test as a non-parametric method (- which do not rely on assumptions that the data are drawn from a given probability distribution). Pearson's chi-square test was used to analyze ordinal and nominal data. Results were reported as odds ratios (OR) or relative risks (RR) with 95\% confidence intervals (CI), estimated directly from $2 \times 2$ tables. All tests were done at the $5 \%$ significance level.

\section{Results}

513 long-term patients residing in seven nursing homes were included. $69 \%$ were women, $31 \%$ men. The mean age was 84.1 years. Nursing home characteristics are demonstrated in Table 1 and use of cardiovascular drugs are shown in Table 2.

\subsection{Atrial fibrillation}

$91(18.8 \%)$ of the 484 patients with recorded electrocardiography had AF. There was no significant difference in the occurrence of AF among nursing homes (Pearson's chi-square test: $p=0.4858) .13(14.3 \%)$ of the 91 AF patients were anticoagulated with warfarin, $85.7 \%$ (78) were not. AF patients were given ASA more than the group without $\mathrm{AF}(\mathrm{OR}=$ 1.73, 95\% CI: $(1.07,2.78)$, Pearson's chi-square test: $p=0.0231)$.

There were significant differences in warfarin treatment to AF-patients among nursing homes (from 0 to $50 \%$ ) as demonstrated in Figure 1. 
The average CHADS2 score for AF patients (91) was ranged from 4 - 6, which corresponds to an annual stroke risk of 8.5-18.2\%. These estimates were based on counting score-giving parameters: Most of the AF patients were older than 75 years old (87\%), giving CHADS2 score " 1 ". We found that $41 \%$ of AF patients had undergone a stroke before, $30 \%$ had ProBNP > $225 \mathrm{pmol} / 1,30 \%$ were given ACE inhibitors/A2 blockers, 13\% anti-diabetics, $57 \%$ diuretics, $23 \%$ beta-blockers and $12 \%$ calcium antagonists, all indicating score-giving illness according to the CHADS2 score.

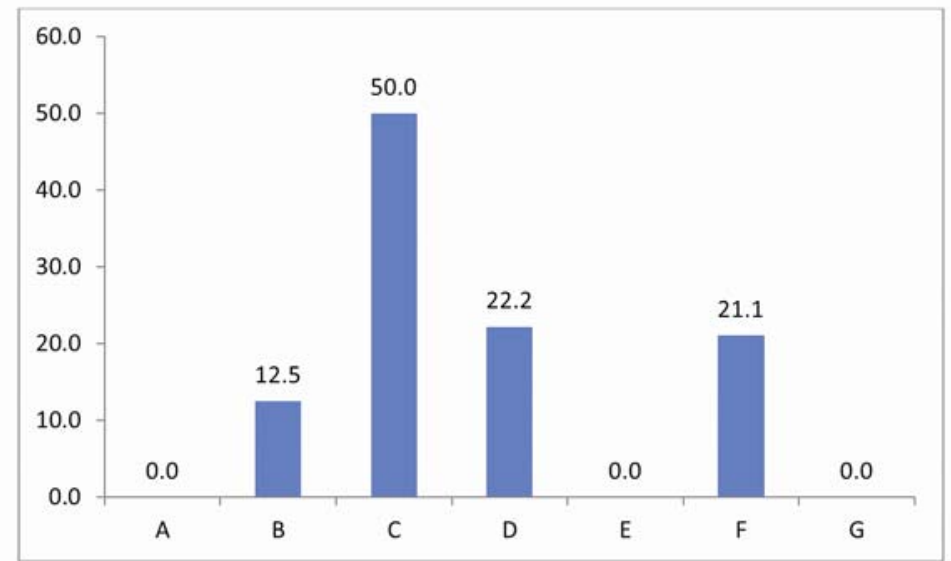

Figure 1. Percentage of long-term patients with atrial fibrillation ( $\mathrm{N}=91)$ receiving warfarin in 7 nursing homes $(A, B \ldots)$ in Bergen, Norway (Pearson's chi-square test: $p=0.0391$ ).

Table 1. Characteristics of the 7nursing homes with long-term patients participating in the city of Bergen, Norway, in 2008 ( $\mathrm{N}=513$ long-term patients)

\begin{tabular}{|c|c|c|c|c|c|c|c|c|c|}
\hline Nursing home & A & B & C & D & $\mathbf{E}$ & $\mathbf{F}$ & G & Total & $P$ \\
\hline $\mathrm{N}$ & 83 & 77 & 39 & 85 & 82 & 101 & 46 & 513 & \\
\hline $\begin{array}{l}\text { No. of places } \\
\text { (total/long/short) }\end{array}$ & $108 / 88 / 20$ & $84 / 63 / 21$ & $66 / 31 / 35$ & $90 / 90 / 0$ & $107 / 81 / 26$ & $131 / 99 / 32$ & $64 / 18 / 46$ & $650 / 500 / 150$ & \\
\hline Location in city & suburb & $\begin{array}{l}\text { inner } \\
\text { city }\end{array}$ & suburb & suburb & inner city & suburb & suburb & & \\
\hline $\begin{array}{l}\text { Doctors' hours } \\
\text { per place per } \\
\text { week }\end{array}$ & 0.4 & 0.3 & 0.5 & 0.3 & 0.4 & 0.4 & 0.5 & 0.4 & \\
\hline Men (\%) & 33.7 & 33.8 & 28.2 & 26.7 & 21.0 & 37.6 & 30.4 & 30.2 & $0.273^{*}$ \\
\hline Age (years) & & & & & & & & & \\
\hline Mean & 86.7 & 85.2 & 84.7 & 84.9 & 88.2 & 79.6 & 82.2 & 84.4 & $<0.001^{* *}$ \\
\hline $\begin{array}{l}\text { Standard } \\
\text { deviation }\end{array}$ & 7.6 & 10.7 & 7.5 & 9.1 & 6.8 & 15.7 & 10.0 & & \\
\hline Length (days) & & & & & & & & & \\
\hline Mean & 990.0 & 901.5 & 973.1 & 946.1 & 1728.9 & 1383.1 & 1055.2 & 1171.5 & $<0.001^{* *}$ \\
\hline $\begin{array}{l}\text { Standard } \\
\text { deviation }\end{array}$ & 1102.9 & 1038.9 & 747.8 & 849.6 & 1075.2 & 1299.9 & 873.43 & & \\
\hline $\begin{array}{l}\text { Non-demented } \\
\mathrm{n}=511(\%)\end{array}$ & 20.7 & 31.6 & 0.0 & 29.4 & 41.5 & 20.8 & 19.6 & 23.4 & $<0.001^{*}$ \\
\hline Deviation (\%) & -2.7 & 8.2 & -23.4 & 6.0 & 18.1 & -2.6 & -3.8 & & \\
\hline $\begin{array}{l}\text { Suffered stroke } \\
n=426(\%)\end{array}$ & 32.4 & 10.2 & 28.2 & 35.4 & 21.5 & 30.0 & 15.4 & 24.7 & $0.009^{*}$ \\
\hline Deviation (\%) & 7.7 & -14.5 & 3.5 & 10.7 & -3.2 & 5.3 & -9.3 & & \\
\hline
\end{tabular}

*Pearson Chi-square; **Kruskal-Wallis test 
Table 2. Use of cardiovascular drugs for long-term patients in 7 nursing homes in Bergen, Norway. Left column shows the different Anatomical Therapeutic Chemical (ATC) drug groups. For each drug group and nursing home the percentage of patients using drugs within the relevant group is shown along with the deviation from the expected average.

\begin{tabular}{|c|c|c|c|c|c|c|c|c|}
\hline Nursing home & A & B & $\mathbf{C}$ & $\mathbf{D}$ & $\mathbf{E}$ & $\mathbf{F}$ & $\mathbf{G}$ & All \\
\hline $\mathrm{N}$ & 83 & 77 & 39 & 85 & 82 & 101 & 46 & 513 \\
\hline \multicolumn{9}{|l|}{ ATC drug group } \\
\hline $\mathrm{C} 09, \mathrm{ACE} / \mathrm{A} 2 \mathrm{~B}, \mathrm{ACEI}$ and A2 -blockers (\%) & 14.46 & 12.99 & 17.95 & 21.18 & 9.76 & 17.82 & 19.57 & 16.25 \\
\hline deviation & -1.79 & -3.26 & +1.70 & +4.93 & -6.49 & +1.57 & +3.32 & \\
\hline B01A, antithrombotics (\%) & 21.69 & 46.75 & 43.59 & 43.53 & 29.27 & 27.72 & 50.00 & 37.51 \\
\hline deviation & -15.82 & +9.24 & +3.09 & +6.08 & -8.24 & -9.79 & +12.49 & \\
\hline B01A, Albyl (\%) & 20.48 & 41.56 & 23.8 & 35.29 & 24.39 & 19.80 & 47.83 & 30.45 \\
\hline deviation & -9.97 & +11.11 & -6.65 & +4.84 & -6.06 & -10.65 & +17.38 & \\
\hline B01AA03, warfarin (\%) & 3.23 & 3.90 & 15.38 & 5.88 & 0.22 & 3.96 & 2.17 & 4,96 \\
\hline deviation & -1.73 & -1.06 & +10.42 & +0.92 & -4.74 & -1.00 & -2.79 & \\
\hline C03, diuretics (\%) & 38.55 & 33.77 & 48.72 & 45.88 & 50.0 & 25.74 & 26.09 & 38.80 \\
\hline deviation & -0.25 & -5.03 & +9.92 & +7.08 & +11.20 & -13.06 & -12.71 & \\
\hline C07, beta-.blockers (\%) & 13.25 & 20.78 & 23.08 & 24.71 & 13.41 & 15.84 & 19.57 & 18.66 \\
\hline deviation & -5.41 & +2.12 & +4.42 & +6.05 & -5.25 & -2.82 & +0.91 & \\
\hline C08, calcium channel blockers (\%) & 7.23 & 12.99 & 2.56 & 9.41 & 7.32 & 3.96 & 8.70 & 7.45 \\
\hline deviation & -0.22 & +5.54 & -4.89 & +1.96 & -0.13 & -3.49 & +1.25 & \\
\hline
\end{tabular}

$120(23.4 \%)$ of the total cohort $(\mathrm{N}=513)$ had at least one incident of stroke. 67 (55.8\%) of patients who had suffered a stroke received some kind of antithrombotic treatment $(\mathrm{ATC}=\mathrm{B} 01 \mathrm{~A}) .10(8.3 \%)$ of these patients were given warfarin. 9 (24.3\%) of 37 patients with both stroke and AF were given warfarin while $27(73.0 \%)$ were given warfarin or some other antithrombotic treatment $(\mathrm{B} 01 \mathrm{AB} / \mathrm{B} 01 \mathrm{AC})$.

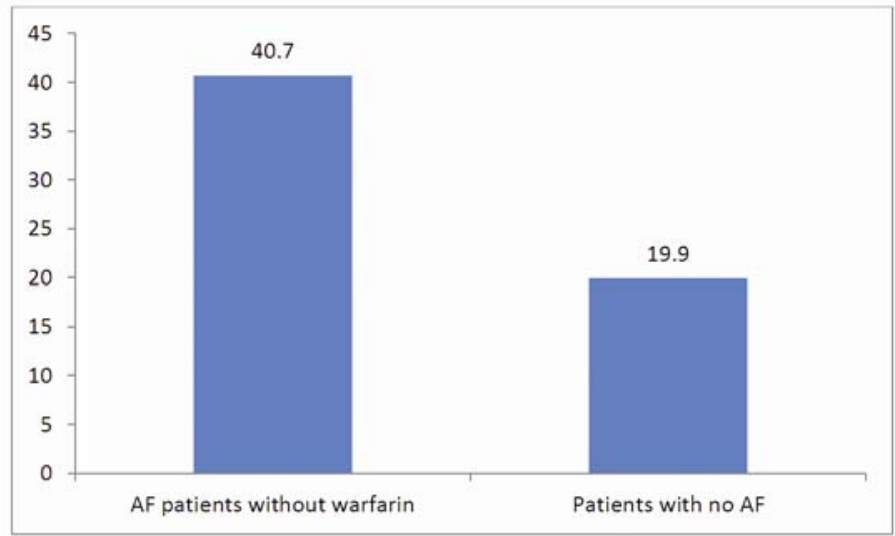

Figure 2. Difference in prevalence (\%) of stroke suffered, between patients with AF without warfarin (37/91) as compared with patients without AF (78/391) among long-term nursing home patients in Bergen, Norway. $(p<0.0001,95 \%$ CI $9.74 \%$ to $32.27 \%)$. 
Patients with AF not receiving warfarin had strokes significantly more often $(37 / 91=40.7 \%)$ than those without AF $(78 / 391=19.9 \%)(\mathrm{N}=484$, odds ratio $=2.75,95 \% \mathrm{CI}$ : $(1.69,4.47)$, Pearson's chi-square: $p<0.0001)$. Patients with AF were 2.75 times more likely to have a stroke suffered than patients without AF (see Figure 2).

\subsection{Heart failure/ ProBNP}

$59(13.2 \%)$ of the patients had ProBNP $>225 \mathrm{pmol} / \mathrm{L}$. The average ProBNP value for all patients was $112.7 \mathrm{pmol} / \mathrm{L}(\mathrm{N}=$ 447, SD 174.8, 95\% CI: 96.5 to 129.0). There was no difference in average ProBNP values among nursing homes (ANOVA with Tukey-Kramer). Of cardiovascular related drugs, diuretics and heart glycosides were used significantly more in patients with ProBNP $>225 \mathrm{pmol} / \mathrm{L}$. Of the 36 patients with ProBNP $>225 \mathrm{pmol} / \mathrm{L}$ and adequate renal function (eGFR $>50 \mathrm{ml} / \mathrm{min}$.), 8 (22.0\%) were given ACE/A2B. The different cardiovascular drugs used in patients with ProBNP $>225 \mathrm{pmol} / \mathrm{L}$ is presented in Figure 3.

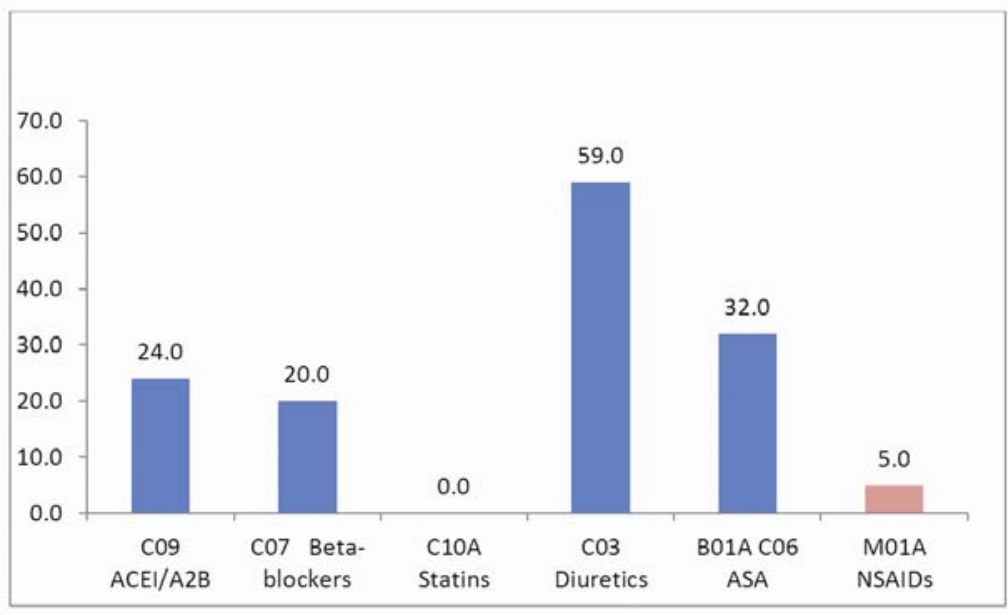

Figure 3. Percentage of patients with ProBNP $>225 \mathrm{pmol} / \mathrm{l}(\mathrm{N}=59)$ using different heart failure treatments and NSAIDs (which are probably contraindicated).

Comparing the proportion patients using ACE -inhibitor or A2-blocker between the two groups of patients; A, with high proBNP $(>225 \mathrm{pmol} / \mathrm{L}$ ) and adequate renal function (eGFR $>60 \mathrm{ml} / \mathrm{min}),(7 / 22)$ and $\mathrm{B}$; those not having high ProBNP but adequate renal function (66/353), no significant difference was found (Pearson's chi -square test: $p=0.2370$ ).

Patients younger than the median age $(\mathrm{N}=221,86.5$ Years) had an average ProBNP of $77 \mathrm{pmol} / \mathrm{L}$ and patients older that the median age $(\mathrm{N}=225)$ had an average ProBNP of $145 \mathrm{pmol} / \mathrm{L}$ (Wilcoxon $p<0.0001)$. Patients less than the median weight $(61.1 \mathrm{~kg})$ had an average ProBNP of $125 \mathrm{pmol} / \mathrm{L}$ and patients more than the median weight had an average ProBNP $=96 \mathrm{pmol} / \mathrm{L}($ Wilcoxon, $p<0.0001)$.

Spearman's correlation between ProBNP and eGFR was -0.3914 $(n=446 ; p<0.001)$ and doing a linear regression for sqrt(proBNP) on sqrt(eGFR) gave the following equation:

$$
\sqrt{\text { proBNP }}=19.457163-1.267237 \times \sqrt{\mathrm{eGFR}}
$$

and an R-squared of 0.1234 (see Figure 4). Having adequate renal function (eGFR $>60 \mathrm{ml} / \mathrm{min}$ ) thus predicted a ProBNP $<92.93 \mathrm{pmol} / \mathrm{l}(=19.457163-1.267237 \times \sqrt{60})$ and $\mathrm{eGFR}=12.37 \mathrm{ml} / \mathrm{min}$ is the renal function which predicts a ProBNP $=$ $225 \mathrm{pmol} / \mathrm{l}\left(\mathrm{x}=((\sqrt{2} 25-19.457163) / 1.267237)^{2}=12.3709014\right)$. No patients in our cohort $(\mathrm{N}=513)$ had an eGFR that low. 
From a multiple linear regression analysis of the square root of proBNP on age, weight and the square root of eGFR we found the following prediction equation:

$$
\operatorname{Pr} o B N P=(17.651306+0.0630223 \times \text { age }-0.070138 \times \text { weight }-1.17 \times \sqrt{e G F R})^{2}
$$

For example for an 80 -year-old patient weighing $70 \mathrm{~kg}$ and having eGFR $=30$ the predicted ProBNP is $129.39 \mathrm{pmol} / \mathrm{L}$.

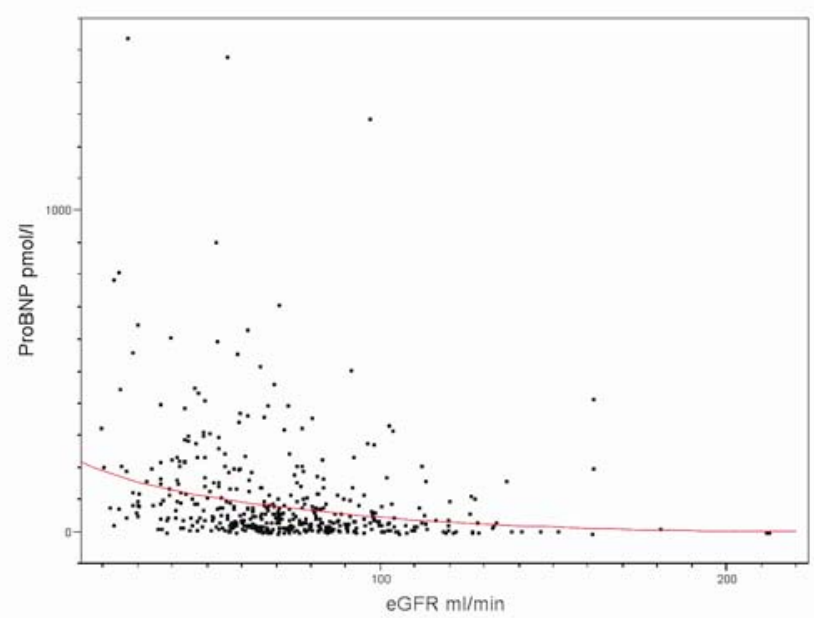

Figure 4. Correlation between ProBNP and eGFR among 446 long-term patients in nursing homes in Bergen, Norway (median age 86.5 years, median weight $61.2 \mathrm{~kg}$ ). Linear regression for sqrt(proBNP) on sqrt(eGFR) gave the following equation: sqrt(proBNP) $=19.457163-1.267237 *$ sqrt(eGFR) and an R-squared of 0.1234 . eGFR $12.37 \mathrm{ml} / \mathrm{min}$. is the renal function which predicts a ProBNP $=225 \mathrm{pmol} / \mathrm{L}\left(\mathrm{x}=((\operatorname{sqrt}(225)-19.457163) / 1.267237){ }^{\circ} 2=12.3709014\right)$. eGFR 60 $\mathrm{ml} / \mathrm{min}$. predicts ProBNP $92.93 \mathrm{pmol} / \mathrm{L}$.

\section{Discussion}

The prevalence of AF among long-term nursing home residents was 18.8\% (91 of 484 ECG'ed). Of these patients, $14.3 \%$ (13) were treated with warfarin and $41.8 \%$ (38) had no antithrombotic treatment at all. The estimated CHADS2 score-based annual stroke risk for this AF-population was between 8.5 and 18.2\%. Of 36 patients with ProBNP $>225$ $\mathrm{pmol} / 1$ and adequate renal function, $22.0 \%$ were treated with ACEI/A2B. There were significant differences in treatment of AF and use of heart failure drugs in patients with ProBNP $>225 \mathrm{pmol} / \mathrm{L}$ among nursing homes in the study.

The role of nursing homes in the delivery of social and healthcare services differs among countries as well as within countries. These differences may influence the health issue landscape and composition of staff. Thus comparisons and generalizations based on our findings should be made with care.

\section{Limitations of the study}

It may be claimed that using ProBNP as the only parameter to diagnose insufficiently or non- treated heart failure weakens the study and most procedures in force recommend echocardiogram to diagnose heart failure. On the other hand, an echocardiogram is often impractical as a diagnostic tool for nursing home patients both due to equipment price and physician qualifications. Transporting patients to a specialist cannot always be recommended for these frail patients either. 
The cut-off value of ProBNP as a diagnostic tool for heart-failure in need of treatment, in different populations, is a matter of discussion. The high median age in our cohort made us go for a relatively high cut-off value (as increasing age leads to increasing ProBNP levels) even though that weakened sensitivity of the test. The main purpose of our study was however to examine if under-treatment existed in heart failure patients. Therefore, specificity (the proportion of negatives in the test which are correctly identified) was more important than sensitivity (proportion of actual positives which are correctly identified). We needed to be fairly sure to exclude healthy patients, missing some sick patients however, strengthens the under-treatment conclusion.

The identified risk by elevated ProBNP, whether it's a risk for death or a risk for heart failure hospitalization, lower values are better, higher values are worse. What one also knows, based on the data from Val-HeFT, is that while a single measurement is useful, serial measurements seem to inform even better prognostic value. This also refers to patients above $75^{[14-16]}$.

Cut-off limits of ProBNP as a diagnostic and prognostic tool in heart failure are discussed in numerous studies. In one study (mean age 73 years, followed for 6 years and registering all cardiovascular mortality) persons with ProBNP above $200 \mathrm{pmol} / \mathrm{L}$ had higher mortality ${ }^{[17]}$. In another study, 24 out of 25 patients were classified correctly with regard to heart failure, as compared with cardiac echo, using a ProBNP cut-off of $223 \mathrm{pmol} / \mathrm{L}^{[10]}$.

Our results of bivariate fits of ProBNP by eGFR, weight and age (which are the known biasing factors), lead us to the conclusion that nursing home patients with a ProBNP $>225 \mathrm{pmol} / \mathrm{L}$ were more likely to have heart failure and, above this level, the high ProBNP values were not caused by high age, low weight or renal failure.

\subsection{Atrial fibrillation}

We found that $18.8 \%$ (91) of the patients had AF in our study population. The prevalence of AF has been found to be $17 \%$ for patients over 65 years and to increase with age ${ }^{[18]}$. Our prevalence is comparable to earlier findings and age groups. Patients with AF, older than 65 , have been consistently undertreated with anticoagulants ${ }^{[19]}$. This is consistent with our finding that the warfarin treatment rate was low (14.3\%). Even a warfarin treatment rate of about $65 \%$ of elderly AF-patients is considered problematic by several authors ${ }^{[9,20]}$. In our study, we found a significant increase in stroke prevalence in AF patients not treated with warfarin, which illustrates under-treatment. Reasons for low treatment rates might be fear of intracranial haemorrhage and falls ${ }^{[20]}$ but with systematic monitoring the risks associated with oral anticoagulation treatment appears to be low ${ }^{[21]}$. To start life-prolonging treatments may not always be as obvious to do in nursing home patients compared to younger patient groups. Suffering involved with stroke is considerable, however, and should be prevented if possible, at all ages.

Based on our estimates the stroke risk among nursing home residents with AF was 8.5-18.2\%, considerably above 5.6\% which is considered the highest bleeding risk score according to Shireman et al. ${ }^{[9]}$. Increased risk of bleeding episodes on warfarin treatment usually occurs among the elders aged within two months of start-up ${ }^{[2]}$. On the other hand, increased CHADS2 score (4-6) in the oldest (>85) population may increase bleeding risk ${ }^{[23]}$. Treatment must always be individualized therefore.

McCormick et al. ${ }^{[24]}$ found that AF was present in 429 (17\%) of 2,587 long-term care residents. Overall, $42 \%$ of these AF patients were receiving warfarin. This is consistent with our study when it comes to AF prevalence and more in line with our own opinion of a reasonable treatment level of frail nursing home patients than our own findings.

\subsection{Heart failure/ ProBNP}

We found 13.2\% (59) had a higher ProBNP (> $225 \mathrm{pmol} / \mathrm{L}$ ). 8-10\% was the prevalence rate for heart failure in earlier studies ${ }^{[25]}$. Only ten $(16.7 \%)$ of the patients were given both ACE/A2B and diuretics, which suggests under-treatment. This impression is reinforced by the lack of significant ACE/A2B differences in treatment rates between the patient group 
with high ProBNP and normal renal function (eGFR $>60 \mathrm{ml} / \mathrm{min}$ - giving a therapeutic indication without renal contraindication) compared to the rest of the cohort.

A high proportion of renal failure among the elderly has been considered to engender reservations in prescribing ACE inhibitors for this patient group ${ }^{[26]}$. However, it is not appropriate to withhold ACE inhibitors for heart failure in patients with only mild renal failure ${ }^{[27,28]}$. Our findings show a low treatment rate in patients with adequate renal function as well.

\section{I mprovement strategies}

It has been claimed that the marginalization of physicians in the nursing home is threatening the overall care of increasingly frail nursing home residents who have medically complex illnesses ${ }^{[29]}$. Staffing by trained doctors seems to be needed as well as training programs in treatment guidelines for AF and heart failure. Modern technological tools may be a way to increase treatment rate of warfarin to AF patients and ACE-inhibitors and A2-blockers to heart failure patients. Electronic patient records with reminders (e.g. "this patient has ProBNP $>250 \mathrm{pmol} / \mathrm{L}$ and normal renal function but receives no ACE-inhibitor or A2-blocker") have been proven effective in general practice and hospitals ${ }^{[30,31]}$. Until now such tools have only been used or tested in a limited number of nursing homes ${ }^{[32]}$.

\section{Conclusion}

Long-term patients with atrial fibrillation and heart failure in nursing homes are treated inadequately and dissimilarly. Strategies are needed to improve quality of cardiovascular treatments. Recording the irregular patient pulse by nurses and doctors and measuring ProBNP regularly may improve this. ProBNP levels in nursing home patients are probably not seriously biased by patient weight, age and renal function at levels above $225 \mathrm{pmol} / \mathrm{L}$.

\section{Acknowledgements}

All 24 medical students from the Faculty of Medicine and Dentistry at the University of Bergen and personnel at the 7 participating nursing homes in Bergen. Dr Kjell-Harald Arntzen, Cardiologist. The study was funded by a grant from the Norwegian Research Council.

\section{References}

[1] Residents in institutions for the elderly and disabled, by age [Internet]. 1992-2009. Available from: http://www.ssb.no/pleie_en/tab-2010-07-08-02-en.html

[2] Norwegian Ministry of Health and Care Services. The Coordination Reform. Oslo: Norwegian ministry of health and care services; 2009.

[3] Ruths S, Straand J, Nygaard HA: Psychotropic drug use in nursing homes-diagnostic indications and variations between institutions. Eur J Clin Pharmacol. 2001; 57(6-7): 523-528. http://dx.doi.org/10.1007/s002280100348

[4] Mant JW, Richards SH, Hobbs FD, Fitzmaurice D, Lip GY, Murray E, et al. Protocol for Birmingham Atrial Fibrillation Treatment of the Aged study (BAFTA): a randomised controlled trial of warfarin versus aspirin for stroke prevention in the management of atrial fibrillation in an elderly primary care population [ISRCTN89345269]. BMC Cardiovasc Disord. 2003; 3: 9. PMid:12939169 http://dx.doi.org/10.1186/1471-2261-3-9

[5] Conway DS, Heeringa J, Van Der Kuip DA, Chin BS, Hofman A, Witteman JC, Lip GY. Atrial fibrillation and the prothrombotic state in the elderly: the Rotterdam Study. Stroke. 2003; 34(2): 413-417. PMid:12574552 http://dx.doi.org/10.1161/01.STR.0000051728.85133.32

[6] Brophy MT, Snyder KE, Gaehde S, Ives C, Gagnon D, Fiore LD. Anticoagulant use for atrial fibrillation in the elderly. J Am Geriatr Soc. 2004; 52(7): 1151-1156. PMid:15209654 http://dx.doi.org/10.1111/j.1532-5415.2004.52314.x

[7] Ceia F, Fonseca C, Mota T, Morais H, Matias F, Costa C, et al. Aetiology, comorbidity and drug therapy of chronic heart failure in the real world: the EPICA substudy. Eur J Heart Fail. 2004; 6(6): 801-806. PMid:15542420 
[8] Tveit A: [New international guidelines on antithrombotic therapy in atrial fibrillation]. Tidsskr Nor Laegeforen. 2009; 129(13): 1332-1335. PMid:19561659 http://dx.doi.org/10.4045/tidsskr.08.0448

[9] Shireman TI, Mahnken JD, Howard PA, Kresowik TF, Hou Q, Ellerbeck EF. Development of a contemporary bleeding risk model for elderly warfarin recipients. Chest. 2006; 130(5):1390-1396. PMid:17099015 http://dx.doi.org/10.1378/chest.130.5.1390

[10] Arques S, Roux E, Sbragia P, Pieri B, Gelisse R, Luccioni R, Ambrosi P. Usefulness of bedside tissue Doppler echocardiography and B-type natriuretic peptide (BNP) in differentiating congestive heart failure from noncardiac cause of acute dyspnea in elderly patients with a normal left ventricular ejection fraction and permanent, nonvalvular atrial fibrillation: insights from a prospective, monocenter study. Echocardiography. 2007; 24(5): 499-507. PMid:17456069 http://dx.doi.org/10.1111/j.1540-8175.2007.00418.x

[11] Zdrenghea D, Pop D, Ilea M, Bodisz G, Malai A, Zdrenghea M. The acute effect of Metoprolol upon NT-proBNP level in patients with congestive heart failure. Rom J Intern Med. 2009; 47(1): 35-40. PMid:19886067

[12] Grewal J, McKelvie R, Lonn E, Tait P, Carlsson J, Gianni M, et al. BNP and NT-proBNP predict echocardiographic severity of diastolic dysfunction. Eur J Heart Fail. 2008; 10(3): 252-259. PMid:18331967 http://dx.doi.org/10.1016/j.ejheart.2008.01.017

[13] Huelsmann M, Neuhold S, Strunk G, Moertl D, Berger R, Prager R, et al. NT-proBNP has a high negative predictive value to rule-out short-term cardiovascular events in patients with diabetes mellitus. Eur Heart J. 2008; 29(18): 2259-2264. PMid:18650200 http://dx.doi.org/10.1093/eurheartj/ehn334

[14] Hradec J, Krupicka J, Janota T. [Will the therapy of chronic heart failure be guided by plasma levels of natriuretic peptides?]. Cas Lek Cesk. 2009; 148(8): 383-388. PMid:19899725

[15] Pfisterer M, Buser P, Rickli H, Gutmann M, Erne P, Rickenbacher P, et al. BNP-guided vs symptom-guided heart failure therapy: the Trial of Intensified vs Standard Medical Therapy in Elderly Patients With Congestive Heart Failure (TIME-CHF) randomized trial. JAMA. 2009; 301(4): 383-392. PMid:19176440 http://dx.doi.org/10.1001/jama.2009.2

[16] Coletta AP, Cullington D, Clark AL, Cleland JG. Clinical trials update from European Society of Cardiology meeting 2008: TIME-CHF, BACH, BEAUTIFUL, GISSI-HF, and HOME-HF. Eur J Heart Fail. 2008; 10(12):1264-1267. PMid:19008149 http://dx.doi.org/10.1016/j.ejheart.2008.10.002

[17] Alehagen U, Goetze JP, Dahlstrom U. Reference intervals and decision limits for B-type natriuretic peptide (BNP) and its precursor (Nt-proBNP) in the elderly. Clin Chim Acta. 2007; 382(1-2): 8-14. PMid:17433809 http://dx.doi.org/10.1016/j.cca.2007.03.005

[18] Bozinovic S, Vojvodic N, Stajkovic Z. [Atrial fibrillation in a defined population of elderly persons]. Vojnosanit Pregl. 1999; 56(1): 21-25. PMid:10230329

[19] Carlsson J, Tebbe U, Rox J, Harmjanz D, Haerten K, Neuhaus KL, et al. Cardioversion of atrial fibrillation in the elderly. ALKK-Study Group. Arbeitsgemeinschaft Leitender Kardiologischer Krankenhausaerzte. Am J Cardiol. 1996; 78(12):1380-1384. http://dx.doi.org/10.1016/S0002-9149(96)00647-9

[20] Hylek EM, D'Antonio J, Evans-Molina C, Shea C, Henault LE, Regan S. Translating the results of randomized trials into clinical practice: the challenge of warfarin candidacy among hospitalized elderly patients with atrial fibrillation. Stroke. 2006; 37(4):1075-1080. PMid:16527999 http://dx.doi.org/10.1161/01.STR.0000209239.71702.ce

[21] Bordin P, Mazzone C, Pandullo C, Goldstein D, Scardi S. Morbidity and mortality in 229 elderly patients with nonrheumatic atrial fibrillation. A five-year follow-up. Ital Heart J. 2003; 4(8): 537-543. PMid:14564980

[22] Hylek EM, Evans-Molina C, Shea C, Henault LE, Regan S. Major hemorrhage and tolerability of warfarin in the first year of therapy among elderly patients with atrial fibrillation. Circulation. 2007; 115(21): 2689-2696. PMid:17515465 http://dx.doi.org/10.1161/CIRCULATIONAHA.106.653048

[23] Poli D, Antonucci E, Marcucci R, Fatini C, Alterini B, Mannini L, et al. Risk of bleeding in very old atrial fibrillation patients on warfarin: relationship with ageing and CHADS2 score. Thromb Res. 2007; 121(3):347-352. PMid:17597186

[24] McCormick D, Gurwitz JH, Goldberg RJ, Becker R, Tate JP, Elwell A, et al. Prevalence and quality of warfarin use for patients with atrial fibrillation in the long-term care setting. Arch Intern Med. 2001; 161(20): 2458-2463. PMid:11700158 http://dx.doi.org/10.1001/archinte.161.20.2458

[25] Kupari M, Lindroos M, Iivanainen AM, Heikkila J, Tilvis R. Congestive heart failure in old age: prevalence, mechanisms and 4-year prognosis in the Helsinki Ageing Study. J Intern Med. 1997; 241(5): 387-394. PMid:9183306 http://dx.doi.org/10.1046/j.1365-2796.1997.129150000.x

[26] Zuccala G, Onder G, Pedone C, Cesari M, Marzetti E, Cocchi A, et al. Use of calcium antagonists and worsening renal function in patients receiving angiotensin-converting-enzyme inhibitors. Eur J Clin Pharmacol. 2003; 58(10): 695-699. PMid:12610747

[27] Mann JF. Cardiovascular risk in patients with mild renal insufficiency: implications for the use of ACE inhibitors. Presse Med. 2005; 34(18): 1303-1308. http://dx.doi.org/10.1016/S0755-4982(05)84178-8 
[28] Elung-Jensen* T, Heisterberg J, Kamper AL, Sonne J, Strandgaard S, Larsen NE. High serum enalaprilat in chronic renal failure. J Renin Angiotensin Aldosterone Syst. 2001; 2(4): 240-245. PMid:11881130

[29] Katz PR, Karuza J, Intrator O, Mor V. Nursing home physician specialists: a response to the workforce crisis in long-term care. Ann Intern Med. 2009; 150(6): 411-413. PMid:19293074

[30] Ornstein S, Jenkins RG, Nietert PJ, Feifer C, Roylance LF, Nemeth L, et al. A multimethod quality improvement intervention to improve preventive cardiovascular care: a cluster randomized trial. Ann Intern Med. 2004; 141(7): 523-532. PMid:15466769

[31] Kawamoto K, Houlihan CA, Balas EA, Lobach DF. Improving clinical practice using clinical decision support systems: a systematic review of trials to identify features critical to success. Bmj. 2005; 330(7494): 765. PMid:15767266 http://dx.doi.org/10.1136/bmj.38398.500764.8F

[32] Kruger K, Strand L, Geitung JT, Eide GE, Grimsmo A: Can electronic tools help improve nursing home quality? ISRN Nurs. 2011. 